\title{
BRIEF ENCOUNTERS
}

ISSN: 2514-0612

Journal homepage: http://briefencounters-journal.co.uk/BE

Introduction

Author(s): Sandy Balfour

Email: Alexander.Balfour@uea.ac.uk

Source: Brief Encounters, Vol. 5 No. 1 (July 2021), pp. i-ii.

URL: http://briefencounters-journal.co.uk/BE/article/view/276

DOI: $10.24134 /$ be.v5i1.276

(c) Sandy Balfour

License (open-access): This is an open-access article distributed under the terms of the Creative Commons Attribution License 4.0, which permits unrestricted use, distribution, and reproduction in any medium, provided the original work is properly cited. No warranty,

express or implied, is given. Nor is any representation made that the contents will be complete or accurate or up to date. The publisher shall not be liable for any actions, claims, proceedings, demand or costs or damages whatsoever or howsoever caused arising directly or indirectly in connection with or arising out of the use of this material. 


\section{Introduction}

\section{Sandy Balfour}

One of the pleasures of editing Brief Encounters is the range of submissions from scholars across the humanities. The editorial call we put out was simple: we welcome rigorous and original articles. That covers a lot of ground, and the response, perhaps predictably, was anything but simple, and a gratifying confirmation that research in the arts and humanities across the CHASE institutions is vibrant, collegiate and relevant. Some of the research and much of the writing of these articles took place in less the ideal conditions. The COVID-19 pandemic disrupted research plans, closed archives and libraries and confined many scholars to their homes and lodgings. The editorial committee for this edition were not able at any point to meet in person; like so many we learned new ways of working, and new ways of collaborating.

When preparing the call for submissions we made two decisions: the first was not to make it about the pandemic (the scale of which we did not fully understand) and the second was not to impose a theme. Anyone who has attended one of the CHASE gatherings, whether in person or online, knows that an astonishing variety of research and thinking in the arts and humanities is being done in our universities. We wanted this issue to reflect that, and we are pleased to say it does. We are pleased also that this is not a 'pandemic issue', although two articles consider consequences of the pandemic. Jack Manzi took the opportunity to think about 'the relationship between isolation, honesty, and one of the central problems posed in Wittgenstein's later work: the problem of dogmatism', while Joseph Jones and Jon Winder, seeing how COVID was challenging our ideas of we live, took the opportunity to write with great sensitivity and insight about the philosophical and historical roots of the binary distinction between work and play.

Even though we did not set a theme, the idea of one exerts a strong pull, here and in much of academia. The temptation is to consider the articles and to try, in an introduction like this, to find what is common — and to call it a theme. We have resisted this siren call. Zhenkai Tong writes about the Chinese 
'May Fourth and New Culture literary canon.' Benedetta Castagna makes specific proposals for new ways of curating the Carlo Crivelli's art in La Marche, and Georgia Haire writes with refreshing candour about the experience of vaginismus and the validity of female pain.

Questions of language and how we communicate arise in other contributions. There are three sections to Brief Encounters: articles, creative pieces and reviews, and the second of these allows for much experimentation. In this issue we include two pieces which explore how people communicate. In The Observer Observed, Elizabeth Chappell, Simon King, and Dominique Baron-Bonarjee reflect on the process of making a film about their experiences as researchers, and how we communicate our findings. Kotryna Garanasvili found new ways to use Virtual Reality technologies to think about the relationship between literature and architecture. Natasha Richards created a film script designed to aid educators working with young people and their experience of sexting. And in the review section Andrew Burton considers theatrical responses to the crisis of global warming. How can theatre reflect on 'hyperobjects' which humans are able to compute but not directly see?

The great sociologist Teodor Shanin, who died in 2020, wrote of 'revolution as a moment of truth', by which he meant that a revolution confronts its participants with the need to examine their assumptions, images and beliefs 'in the merciless light of experience'. Much of public discourse today concerns what sounds, but does not yet feel, like a revolution. What unifies the articles in this edition of Brief Encounters is not their subject matter, nor their theoretical approaches, but the fact that the authors are all people who welcome that merciless light, and seek to shine it clearly and courageously on the full range of human experience, and then to share their findings in a language that is never still and is ever open to the improvisations of all its speakers.

Copyright (C) Sandy Balfour 2021

\footnotetext{
${ }^{1}$ Teodor Shanin, Revolution as a Moment of Truth: Russia 1905-1907, (Yale University Press, 1986), p 184.
} 